\title{
Retracted: Numerical Solution of Nonlinear Fredholm Integrodifferential Equations by Hybrid of Block-Pulse Functions and Normalized Bernstein Polynomials
}

\author{
Abstract and Applied Analysis \\ Received 9 June 2014; Accepted 9 June 2014; Published 16 June 2014 \\ Copyright (C) 2014 Abstract and Applied Analysis. This is an open access article distributed under the Creative Commons \\ Attribution License, which permits unrestricted use, distribution, and reproduction in any medium, provided the original work is \\ properly cited.
}

The paper titled "Numerical Solution of Nonlinear Fredholm Integrodifferential Equations by Hybrid of BlockPulse Functions and Normalized Bernstein Polynomials" [1], published in Abstract and Applied Analysis, has been retracted as an almost identical paper by the same author has been simultaneously submitted to and published in Journal of Computational and Applied Mathematics. The other publication is "Solution of nonlinear Fredholm integrodifferential equations using a hybrid of block pulse functions and normalized Bernstein polynomials," Volume 260, April 2014, Pages 258-265, DOI: 10.1016/j.cam.2013.09.036.

\section{References}

[1] S. H. Behiry, "Numerical solution of nonlinear fredholm integrodifferential equations by hybrid of block-pulse functions and normalized bernstein polynomials," Abstract and Applied Analysis, vol. 2013, Article ID 416757, 8 pages, 2013. 